\title{
PERENCANAAN TRANSPORTASI UMUM TERPADU PADA KAWASAN KOTA MANDIRI (Studi Kasus : Kawasan Bumi Serpong Damai, Kota Tangerang Selatan)
}

\author{
Heru Widodo(1) \\ (1)Perencanaan Wilayah dan Kota, Fakultas Teknik dan Desain, Institut Teknologi dan \\ Sains Bandung (ITSB).
}

\begin{abstract}
Abstrak
Kota Mandiri adalah suatu kawasan yang direncanakan dan dikembangkan tersendiri yang dikembangkan dengan fungsi khusus berkaitan dengan potensi tertentu. Kemudian Kota Mandiri secara ekonomi dan sosial dapat memenuhi kebutuhannya sendiri (paling tidak sebagian besar penduduknya). Selain itu tentunya dalam hal pelayanan infrastruktur dasar juga dapat memenuhi kebutuhannya sendiri, yang salah satunya adalah sistem transportasi umum. Kondisi demikian apabila dari sisi transportasi menjadikan kota mandiri yang seharusnya dapat berdiri sendiri menjadi beban bagi wilayah disekitarnya. Analisis pola guna lahan dan pergerakan memberikan gambaran konsep pengelolaan transportasi umum yang mengikuti bangkitan, tarikan, serta pola pergerakan masyarakat di kawasan BSD. Dari hasil analisis yang dilakukan dapat diambil kesimpulan bahwa dalam pengelolaan transportasi umum di Kota Mandiri perlu membangun transportasi internal dan integrasinya dengan sistem transportasi regional seperti BRT, MRT, dan jaringan transportasi umum regional lainnya. Dalam kasus $B S D$ ini integrasi dilakukan antara transportasi internal BSD dengan jaringan BRT Transjakarta dan jaringan KRL Jabodetabek.
\end{abstract}

Kata Kunci : Kota Mandiri, Transportasi, Integrasi

\section{Pendahuluan}

Transportasi merupakan salah satu permasalahan yang sering terjadi di kawasan perkotaan, dimana permasalahan utama adalah kemacetan lalu lintas. Permasalahan kemacetan lalu lintas memberikan dampak negatif terhadap besarnya biaya transportasi, pemborosan waktu dan energi, serta dampak sosial dan lingkungan. Dalam jangka panjang permasalahan transportasi ini akan berakibat pada turunnya daya saing ekonomi kota serta livability kota bagi kehidupan penduduknya. Begitu pula di Kota Tangerang Selatan, berdasarkan Profil Perhubungan Kota Tangerang Selatan, permasalahan transportasi menjadi salah satu permasalahan klasik yang cukup sulit untuk diselesaikan. Kota Tangerang Selatan saat ini memiliki permasalahan di bidang transportasi yang cukup unik. Kota Tangerang Selatan merupakan salah satu wilayah dari kawasan Metropolitan Jabodetabek dimana kawasan Kota Tangerang Selatan kini dikembangkan bukan hanya menjadi satelit bagi pusat metropolitan Jabodetabek yaitu DKI Jakarta, tapi Kota
Tangerang Selatan saat ini berkembang menjadi pusat kegiatan baru di kawasan metropolitan Jabodetabek.

Salah satu bentuk pengembangan wilayah Kota Tangerang Selatan adalah dengan adanya kawasan terpadu Kota Baru Bumi Serpong Damai (BSD) yang dikembangkan sebagai kawasan mixed-used dimana terdapat berbagai macam aktifitas di kawasan ini seperti permukiman, perkantoran, komersil, pendidikan, jasa dan fungsi kawasan lainnya. Kota Baru Bumi Serpong Damai merupakan kota baru mandiri yang merupakan pionir dari kota baru di Indonesia yang terletak di Kota Tangerang Selatan yang masuk dalam wilayah Provinsi Banten. Perubahan tata guna lahan, peningkatan jumlah dari lahan non terbangun menjadi lahan terbangun, pembangunan infrastruktur dan peningkatan akses transportasi berupa jalan merupakan sebagian dampak yang terjadi akibat adanya Kota Baru Bumi Serpong Damai. Aktivitas permukiman, pendidikan, komersial, dan fasilitas penunjang dari kawasan BSD memberikan kontribusi terhadap emisi gas buang dari sektor 
penggunaan energi, sektor transportasi, dan limbah.

Menurut Sujarto (1993), Kota Mandiri adalah suatu kawasan yang direncanakan dan dikembangkan tersendiri, dikembangkan dengan fungsi khusus berkaitan dengan potensi tertentu. Kemudian Kota Mandiri secara ekonomi dan sosial dapat memenuhi kebutuhan sendiri (paling tidak sebagian besar penduduknya). Selain itu tentunya dalam hal pelayanan infrastruktur dasar juga dapat memenuhi kebutuhannya sendiri, yang salah satunya adalah sistem transportasi umum.

Berdasarkan data Masterplan Pengembangan Kawasan Bumi Serpong Damai (2015), saat ini transportasi umum di kawasan BSD hanya dilayani oleh shuttle BSD dengan tingkat pemenuhan yang masih belum mencukupi dalam hal pengangkutan penumpang maupun pemenuhan cakupan pelayanan jaringan, sehingga masyarakat yang bermukim di kawasan BSD maupun yang beraktifitas di dalam kawasan tersebut lebih banyak menggunakan kendaraan pribadi yang tentu dampaknya dapat mempengaruhi peningkatan emisi gas buang terutama di masa yang akan dating. Namun dibalik permasalahan yang dihadapi, terdapat potensi pengembangan transportasi terintegrasi baik secara internal maupun pergerakan antar wilayah karena saat ini, posisi kawasan BSD berdekatan dengan jaringan transportasi kereta api komuter jaringan Jabodetabek.

Dengan demkian dapat disimpulkan pula bahwa, secara umum permasalahan transportasi di kawasan BSD yang merupakan kawasan kota mandiri mungkin terjadi karena ketidakseimbangan antara penyediaan (supply) jaringan transportasi dengan permintaan (demand) perjalanan dan juga tingkat pelayanan angkutan umum yang rendah sehingga memicu pertumbuhan penggunaan kendaraan pribadi menjadi sangat pesat. Penyelesaiannya secara efektif harus dilakukan sebagai kombinasi antara peningkatan kapasitas jaringan (pengembangan pelayanan angkutan umum) maupun mengelola demand yang ada agar memanfaatkan ketersediaan kapasitas secara optimal yakni dengan menerapkan skema manajemen lalu lintas maupun manajemen kebutuhan transportasi.

\section{Metodologi}

Paper ini menggunakan kajian literatur untuk mendapatkan model integrasi transportasi antara kota mandiri atau kota baru dengan sistem transportasi yang lebih makro atau sistem transportasi perkotaan disekitarnya. Selain itu akan dilakukan pemodelan transportasi sederhana untuk melihat pola pergerakan transportasi serta kaitannya dengan pola tata ruang di kawasan BSD

Menurut Radulovich (2004), integrasi transportasi multimoda secara regional antara kota mandiri dengan wilayah sekitarnya dipengaruhi oleh beberapa faktor antara lain kegiatan ekonomi, penataan kota, jaringan jalan, permukiman dan guna lahan, kondisi sosial, dan lingkungan. Dengan faktor-faktor tersebut dapat diidentifikasi kebutuhan pergerakan suatu kota mandiri terutama untuk kota mandiri yang masyarakatnya melakukan pergerakan keluar dari kawasan ke kawasan lain secara rutin (komuter) adalah dengan merencanakan model integrasi transportasi umum secara efektif, secara umum konsep integrasi transportasi umum kota mandiri dengan kawasan di sekitarnya dapat digambarkan sebagai berikut,

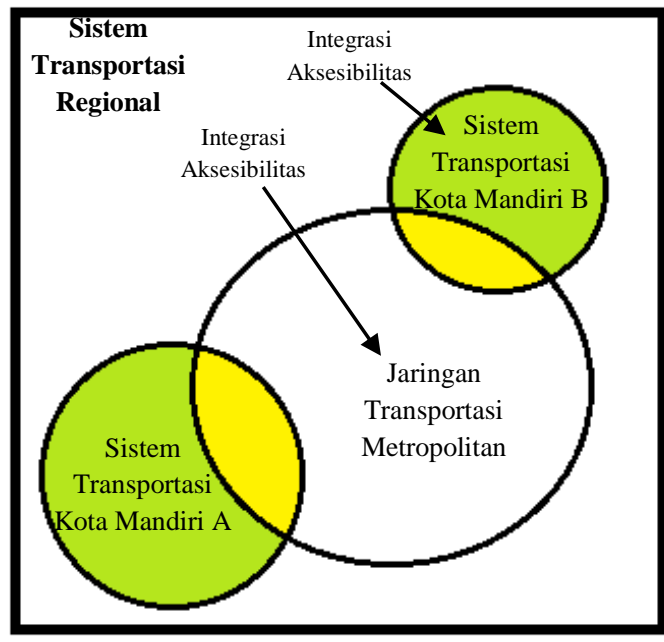

Gambar 1 Konsep Integrasi Transportasi Kota Mandiri dalam Sistem Transportasi Regional Sumber : Radulovich, 2004

Menurut Wei (2013), apabila di suatu kota mandiri terdapat pergerakan transportasi yang cukup besar ke wilayah lainnya atau wilayah perkotaan disekitarnya, maka integrasi sistem transportasi perlu dilakukan. Integrasi sistem transportasi dilakukan dengan mengintegrasikan sistem transportasi lokal di 
dalam kota mandiri dengan sistem jaringan transportasi umum regional yang memiliki kapasitas angkut yang lebih besar seperti jaringan transportasi kereta api, BRT, atau jaringan transportasi umum massal lainnya.

Integrasi transportasi umum yang dimaksud adalah dengan mengintegrasikan jaringan dan simpul antara sistem transportasi berdasarkan potensi bangkitan dan tarikan serta asal tujuan pergerakan masyarakat di dalam kota mandiri maupun keluar wilayah kota mandiri tersebut dengan mempertimbangkan aspek guna lahan, dan pola pergerakan.

Menurut Tamin (1997), dalam kaitan itu hubungan timbal-balik antara tata ruang-transportasi, terdapat beberapa keterkaitan yang secara singkat dapat dijelaskan sebagai berikut:

a. Kebijakan penataan ruang dan interaksinya dengan mekanisme pasar merupakan penentu dari lokasi ruang kegiatan produksi, distribusi, dan konsumsi yang menyebabkan perbedaan karakteristik sosial dan ekonomi setiap kawasan/zona di suatu wilayah;

b. Distribusi ruang kegiatan tersebut di dalam ruang akan membutuhkan/menimbulkan pola interaksi kegiatan secara spasial di dalam sistem transportasi yang menghasilkan pola pergerakan penumpang dan barang;

c. Distribusi jaringan transportasi sesuai dengan struktur yang ada (hirarki, kapasitas, pelayanan) agar menciptakan tingkat keterhubungan spasial antar lokasi (yang bisa dinilai sebagai tingkat aksesibilitas) yang berbeda-beda sesuai dengan kapabilitas dari jaringan transportasi yang tersedia;

d. Kapabilitas jaringan transportasi dalam mengakomodir kebutuhan perjalanan antar lokasi akan menghasilkan kinerja jaringan transportasi secara kuantitatif maupun kualitatif terkait dengan biaya dan waktu perjalanan, kenyamanan, keselamatan, dan keamanan;

e. Distribusi aksesibilitas dalam ruang tersebut berikut dengan indikator kinerja transportasi yang dihasilkannya akan menentukan pemilihan lokasi yang menghasilkan perubahan dalam sistem ruang.

\section{Pembahasan}

\section{a. Pola Guna Lahan Masyarakat di BSD}

Berdasarkan hasil survey dan analisis, kawasan Bumi Serpong Damai (BSD) yang menjadi studi kasus dalam penyusunan pola integrasi angkutan umum antara kota mandiri dan wilayah disekitarnya ini cenderung memiliki guna lahan yang cukup lengkap, namun secara pergerakan masih cukup banyak pergerakan keluar kawasan, atau dapat disimpulkan bahwa guna lahan yang cukup bervariasi di kota mandiri belum dapat mereduksi pergerakan keluar wilayah kota mandiri.

Gambar 2 Tata Guna Lahan Eksisting dan Rencana di Kawasan BSD

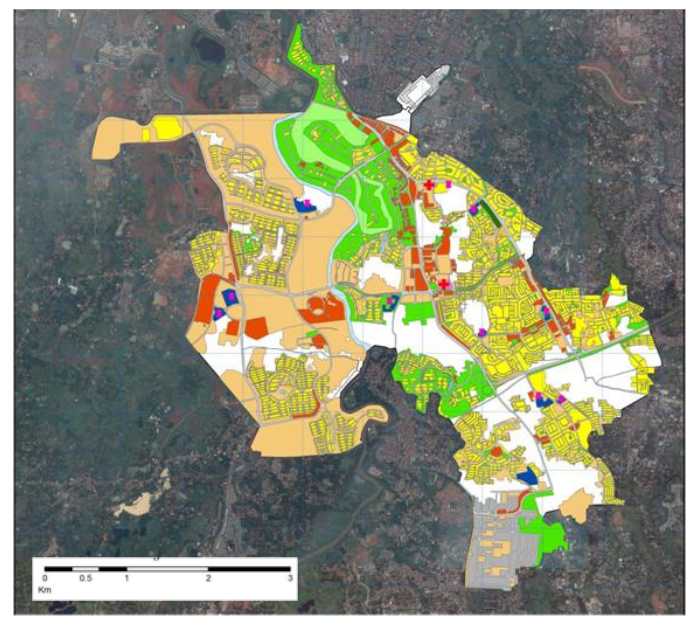

Sumber : BSD City, 2016

Luas wilayah efektif wilayah BSD adalah seluas 2217,24 ha. Bila memperhitungkan luas guna lahan lainnya (sungai, kereta api, dan jalan tol dan sempadannya) seluas 478,91 , maka total luas wiayah menjadi 2.696,15 ha Guna lahan dari BSD City meliputi hunian/residensial, komersial/fasilitas sosial, industri dan perdagangan, dan sarana, taman jalur hijau, saluran dan kolam retensi, serta sarana transportasi (jalan). Berdasarkan hasil kajian BSD City (2014), guna lahan terbesar di BSD City adalah tanah kosong dengan persentase sebesar 40,26\%, kemudian diikutin dengan permukiman (26,32 \%), RTH (14,66\%), dan Komersial $(10,11 \%)$. 


\section{b. Pola Pergerakan Lalu Lintas di BSD}

Pola pergerakan lalu lintas di kawasan BSD tentunya dilihat dari pola jaringan jalan dan pola pergerakan yang ada pada jaringan jalan tersebut. Dari hasil survey dan analisis terkait dengan pola pergerakan di kawasan BSD, terlihat bahwa jaringan jalan yang membentuk pola pergerakan di kawasan ini terdiri dari pergerakan internal, internal eksternal, dan terdapat jaringan jalan arteri yang melewati kawasan BSD yang mengakomodir pergerakan antar eksternal. Pola pergerakan ini didapatkan berdasakan hasil pengamatan di lapangan dan disampaikan dalam gambar berikut,

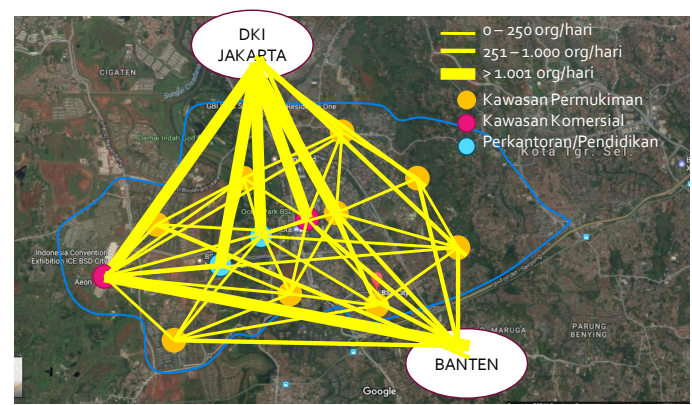

Gambar 2 Pola Pergerakan di Kawasan BSD Sumber : Hasil Survey dan Analisis (2016)

Sedangkan untuk besaran pergerakan di kawasan BSD baik secara internal maupun eksternal, berdasarkan hasil survey dan analisis didapat bahwa pergerakan harian mayoritas masyarakat di kawasan BSD adalah dari dan ke kawasan eksternal yaitu kawasan DKI Jakarta dan Banten, sedangkan untuk pergerakan internal cukup besar menuju kawasan komersil, gambaran yang dapat disampaikan di gambar berikut

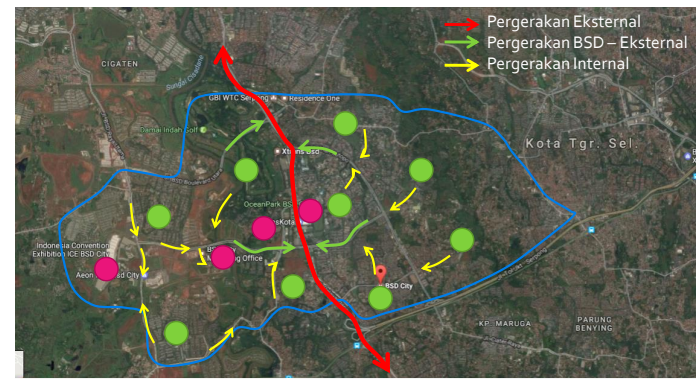

Gambar 3 Desire Line Asal tujuan Pergerakan Sumber : BSD City (2016), Hasil Analisis (2016)
Dari peta desire line asal tujuan pergerakan terlihat bahwa pergerakan terbesar adalah dari kawasan komersial dan perkantoran di BSD menuju kawasan DKI Jakarta dan sebaliknya, sedangkan pergerakan internal rata-rata masih dibawah 250 pergerakan orang per hari nya. Kondisi demikian kembali memperlihatkan bahwa untuk kota mandiri yang cukup representatif seperti BSD City, belum bisa mereduksi pergerakan regional. Pergerakan masyarakat keluar dari BSD maupun masuk masih cukup besar.

\section{c. Sistem Transportasi Eksisting}

Saat ini terdapat transportasi internal dan eksternal di kawasan BSD, yaitu BRT Transjakarta yang berada di dalam kawasan BSD untuk mengakomodir pergerakan eksternal dan angkutan khusus untuk mengakomodir pergerakan internal. Selain itu diluar kawasan BSD terdapat stasiun kereta api yaitu stasiun Serpong dimana terdapat jaringan KRL Jabodetabek, namun belum ada transportasi umum yang mengakomodir pergerakan dari dalam kawasan BSD menuju stasiun Serpong tersebut. 


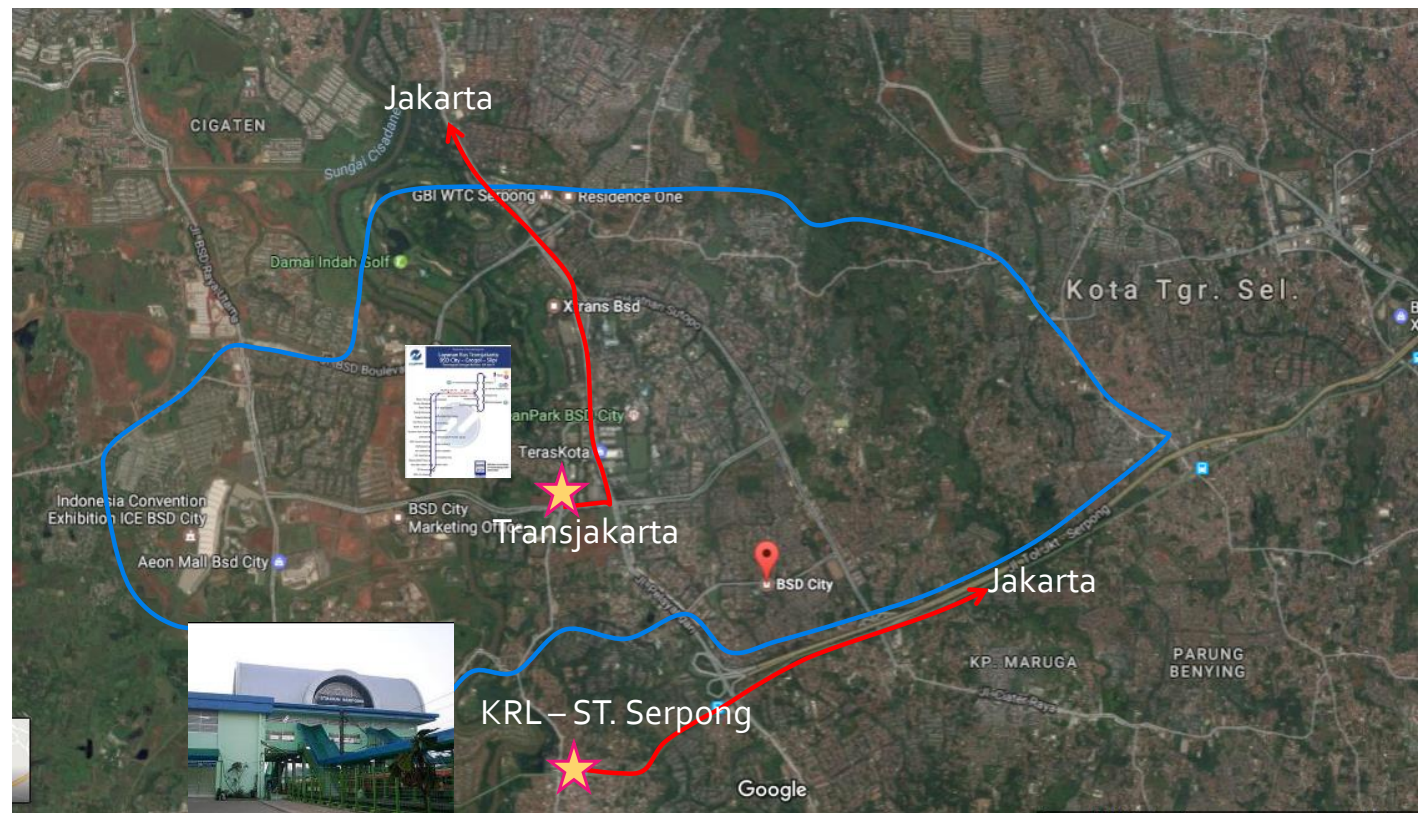

Gambar 5 Sistem Transportasi Eksisting BSD

Sumber : BSD City, 2016

Apabila melihat beberapa kondisi diatas, mulai dari pola pergerakan dari kawasan BSD yang cukup besar, dan bahkan BSD sendiri menjadi pusat tarikan pergerakan dari luar kawasan $\mathrm{BSD}$, tentunya kondisi tersebut tidak dapat dihindari dan harus diakomodir oleh sistem transportasi umum yang representatif.

Dengan melihat kondisi eksisting pergerakan saat ini dan kondisi eksisting transportasi umum di kawasan BSD dan kawasan sekitarnya secara regional, untuk pergerakan internal perlu diakomodir oleh sistem,

kemudian untuk pergerakan dari internal ke eksternal BSD maupun sebaliknya, angkutan umum yang melayani internal tersebut dapat diintergrasikan dengan sistem angkutan umum regional disekitarnya.

\section{Kesimpulan}

Dalam mengembangan sistem transportasi umum di Kota Mandiri khususnya dalam konteks kota Mandiri yang masih memiliki pergerakan eksternal yang cukup besar seperti umumnya kota Mandiri di Indonesia, diperlukan pengembangan angkutan umum internal yang dapat mengakomodir pergerakan internal serta integrasi dengan jaringan transportasi regional seperti BRT ataupun MRT baik rail-based transport maupun road-based transport.

Dalam kasus pengelolaan transportasi di kawasan BSD, perlu dikembangkan sistem transportasi umum baik untuk melayani pergerakan internal maupun eksternal sebagai berikut :

- Untuk pergerakan internal, perlu disediakan angkutan umum semacam shuttle car yang melayani pusat kegiatan komersil,

- perkantoran, pendidikan, dan permukiman yang ada di dalam kawasan BSD.

- Untuk mengakomodir pergerakan eksternal, shuttle car yang melayani pergerakan internal diintegrasikan dengan simpul-simpul transportasi regional antara lain simpul BRT Transjakarta dan KRL Jabodetabek yang berada di stasiun Serpong. Pergerakan eksternal yang dimaksud merupakan pergerakan keluar maupun masuk ke kawasan BSD.

Dalam hal demikian, untuk pengembangan transportasi umum di kawasan Kota Mandiri perlu dipertimbangkan beberapa hal, antara lain:

- Pola guna lahan

- Pola pergerakan eksisting

- Potensi bangkitan dan tarikan

- Jaringan transportasi regional terdekat 
- Konsep pengembangan angkutan umum internal kawasan

- Integrasi angkutan umum internal kawasan dengan jaringan transportasi regional terdekat

\section{Daftar Pustaka}

Ben-Akiva, M.E. and Lerman, S.R. (1985), Discrete Choice Analysis: Theory and Application to Travel Demand, Cambridge: MIT Press

Kusbiantoro, BS. 2013. Bahan Kuliah Perencanaan Transportasi. Program Magister Transportasi SAPPK ITB. Bandung

Manheim, Marvin L., (1979), "Fundamental of Transportation System Analysis", Cambridge: MIT Press.

Ortuzar., Juan de Dios and Luis G Willumsen, (2001). "Modelling Transport, Third Edition". Chichester: John Wiley \& Sons.

Papacostas C. S and Provedouros, (1993), "Transportation Engineering and Planning, Second Edition", New Jersey: Prentice Hall

Sujarto, Djoko, (1993), "Perkembangan Kota Baru, Jurnal Perencanaan Wilayah dan Kota", Bandung: Departemen Teknik Planologi FTSP ITB.

Tamin,O.Z., (1997), "Perencanaan \& Pemodelan Transportasi", Bandung : Penerbit ITB

Tamin,O.Z., (1997), "Menuju Terciptanya Sitem Transportasi Berkelanjutan di Kota-Kota Besa di Indonesia", Bandung : Teknik Sipil ITB

Wei, Heng., Abdollah Moghrabi (2013), "Key Issues in Integrating New Town Development into Urban Transportation Planning", Elsevier 